\title{
Patterns of vertical growth in the face
}

\author{
Surender K. Nanda, D.M.D., M.S.* \\ Ann Arbor, Mich.
}

The purpose of this study was to examine the patterns of facial growth development in subjects with skeletal open-bite and skeletal deep-bite faces. Longitudinal data based on lateral cephalometric. radiographs of 16 male and 16 female subjects, ages 3 through 18 years, were used. These subjects were selected on the basis of lower face height as a percentage of total face height. Persons exhibiting extreme values were selected to create four groups with eight subjects in each group. Curves of absolute and incremental growth for total anterior face height, upper anterior face height, lower anterior face height, posterior face height, and ramal length were analyzed statistically and graphically. It was established that the anterior dimensions of the face demonstrated typologically divergent patterns of development in open- and deep-bite faces. Further, the posterior dimensions of the face did not discriminate between these two typological groups. The female open-bite subjects were earliest in the timing of the adolescent growth spurt, followed in succession by deep-bite fernale subjects, open-bite male subjects, and finally the deep-bite male subjects. The clinical implications of these observations pertain to the timing of orthodontic treatment, the length of retention period, and the prediction of adult occlusal status during the mixed dentition. (Am J Orthod Dentofac Orthop 1988;93:103-16.)

$\mathrm{T}_{\mathrm{w}}$ divergent. ${ }^{1,2}$ Persons with relatively long or disproportionately excessive anterior lower facial heights have also been described by the term "long face syndrome.".

In terms of facial type, an open bite is associated with excessive lower anterior face height relative to the upper face height. Posterior face height tends to be approximately one half the size of the total anterior face height, while ramal length is short. Thus, the discordant dimensions produce a cumulative effect that results in an excessive anterior face height. Most of the characteristics of the deep-bite face are directly opposite to those of the open-bite configuration.

Several linear dimensions have been studied pertaining to the vertical development of the face. These studies have demonstrated that total anterior face height is relatively large in persons with open-bite faces and reduced in persons with deep-bite faces when compared with the average. ${ }^{1,4-18}$ On the other hand, it should be noted that several investigators ${ }^{8,10,15,16}$ have suggested that one of the key factors contributing to the open-bite morphology is a reduction in the posterior height of the face.

Many investigators have confirmed the strong influence of lower anterior face height on the formation

*Professor, Department of Orthodontics, The University of Michigan. of vertical facial disproportions. "Open-bite" subjects are characterized by larger lower vertical face heights when compared with "deep-bite" subjects. ${ }^{1,2,5-7,9-11,17-20}$ In reference to the upper anterior face height, Björk ${ }^{5}$ and Schendel and associates ${ }^{3}$ reported an excessive vertical height of the maxilla in "open-bitc" subjects, while Hapak ${ }^{11}$ and Fields and associates ${ }^{21}$ observed normal upper facial dimensions. These findings are in contrast to those of Atherton, ${ }^{12}$ Muller, ${ }^{8}$ Nahoum, ${ }^{14,22}$ and Siriwat and Jarabak, ${ }^{23}$ who reported a relative deficiency in the vertical maxillary dimension in open-bite subjects.

With respect to posterior facial morphology, Björk ${ }^{5}$ contended that ramal height is excessive in openbite subjects. This finding is not in agreement with the observations of Swinehart, ${ }^{24}$ Sassouni, ${ }^{1,7}$ Muller, ${ }^{8}$ Schudy, ${ }^{2}$ and Sassouni and Nanda, ${ }^{10}$ all of whom reported a considerable deficiency in this dimension, while Fields and associates ${ }^{21}$ observed no differences in posterior facial height among open-bite and deepbite groups. In the "deep-bite" facial type, the relevant linear dimensions of the face present a comparable degree of variation as in the open-bite type, but in opposite proportions. The expression of disharmonious proportions in the facial skeleton can be attributed to the failure of normal, coordinated growth of the various regions of the craniofacial complex in terms of timing, magnitude, and direction. ${ }^{25}$

Trouten and associates ${ }^{26}$ conducted skeletal analyses 
Table I. Comparison of lower face height (LFH) as a percentage of total anterior face height (TAFH) for open- and deep-bite subjects (mean age: female subjects 13 years 6 mos; male subjects 15 years)

\begin{tabular}{|c|c|c|c|c|c|c|}
\hline & \multicolumn{6}{|c|}{ Percentage of LFH to TAFH } \\
\hline & \multicolumn{3}{|c|}{ Male subjects } & \multicolumn{3}{|c|}{ Female subjects } \\
\hline & Mean & $S D$ & Range & Mean & $S D$ & Range \\
\hline Open bite & 60.65 & 1.2 & $59.48-63.24$ & 59.67 & 2.4 & $57.62-62.03$ \\
\hline \multirow[t]{2}{*}{ Deep bite } & 53.61 & 1.3 & $52.34-54.92$ & 53.27 & 1.2 & $48.27-55.45$ \\
\hline & & \multicolumn{2}{|l|}{$\begin{array}{l}\text { Fields and } \\
\text { associates }^{2 I}\end{array}$} & $\begin{array}{c}\text { Subtelny } \\
\text { and Sakuda }\end{array}$ & & Hapak $^{\prime \prime}$ \\
\hline Open & & \multicolumn{2}{|l|}{58.0} & 58.5 & & 58.0 \\
\hline Norm & & \multirow{2}{*}{\multicolumn{2}{|c|}{56.0}} & 55.1 & & - \\
\hline Deep & & & & - & & - \\
\hline
\end{tabular}

of dental open- and deep-bite subjects predicated upon comparison of hypothetic cephalometric measurements based upon Enlow's counterpart analysis. These authors contended that a combination of the various parts of the craniofacial complex is the basis for the vertical dysplasias. Thus, the morphologic basis of an open bite is associated with a large gonial angle, lack of compensating curve of Spee, large vertical posterior maxillary dimension, anteroposterior rotation of maxilla and mid-cranial fossa, and long mandibular corpus. In the deep-bite subjects, the deviations are essentially opposite to the open-bite subjects. Björk ${ }^{5}$ and Sassouni ${ }^{1,7}$ recognized comparable deviations and explained the role of specific structural imbalances. According to these authors, it is particularly relevant to recognize that simultaneous presence of all deviations in the formation of open and deep bites is not required to affect the vertical dysplasia. To date, only one study using longitudinal data ${ }^{27}$ has specifically examined the patterns of development in persons with sagittal and vertical dysplasias of the facial skeleton. Bishara and Jakobsen ${ }^{27}$ described dental and skeletal morphologies using longitudinal data from subjects placed into three groups on the basis of the ratio of posterior to anterior face height and the Frankfort to mandibular plane angle. The specific values differentiating the groups were not identified. The subjects used in Bishara and Jakobsen's study $^{27}$ had acceptable occlusion and no facial disharmony. Similar data ${ }^{28}$ were reported previously to describe the facial changes. Most of the parameters reported $^{27}$ to discriminate the morphology of open- and deep-bite subjects were not significant. It should be noted that the sample used in Bishara and Jakobsen' ${ }^{27}$ study was based upon range of normal relationships.

Most of the studies have been limited to the use of cross-sectional cephalometric data during adolescence (9 to 13 years of age). Several investigators differentiated their sample simply on the presence or absence of dental anterior open or deep bite. ${ }^{22,26}$ Others selected subjects on the basis of proportions of morphologic face height and the mandibular plane angle. ${ }^{16,27}$ The conclusions based upon these studies are ambiguous, have led to confusion, and no compositc picture of pattern of development associated with vertical dysplasias has emerged, preventing appropriate comparison of data from different studies.

The purpose of the present study was to examine the developmental patterns in the faces of persons exhibiting divergent vertical dysplasias. Two fundamental questions were investigated:

1. At what point in postnatal development is it possible to recognize the establishment of facial patterns in open-bite and deep-bite subjects?

2. Do the facial patterns, once identified, tend to persist throughout development?

\section{MATERIALS AND METHODS The sample}

Longitudinal data from annual lateral radiographs of 16 male and 16 female subjects, covering an age span from 3 through 18 years, were used in this study. These data were collected under the auspices of the Child Research Council in Denver, Colo. All subjects were white and had not received orthodontic treatment.

The 32 subjects were drawn from a total sample of 250 persons on the basis of lower face height (ANS-ME) as a percentage of morphologic face height (N-ME). The persons exhibiting the most extreme values at both ends of the distribution were selected to create four groups with eight subjects in each group. 


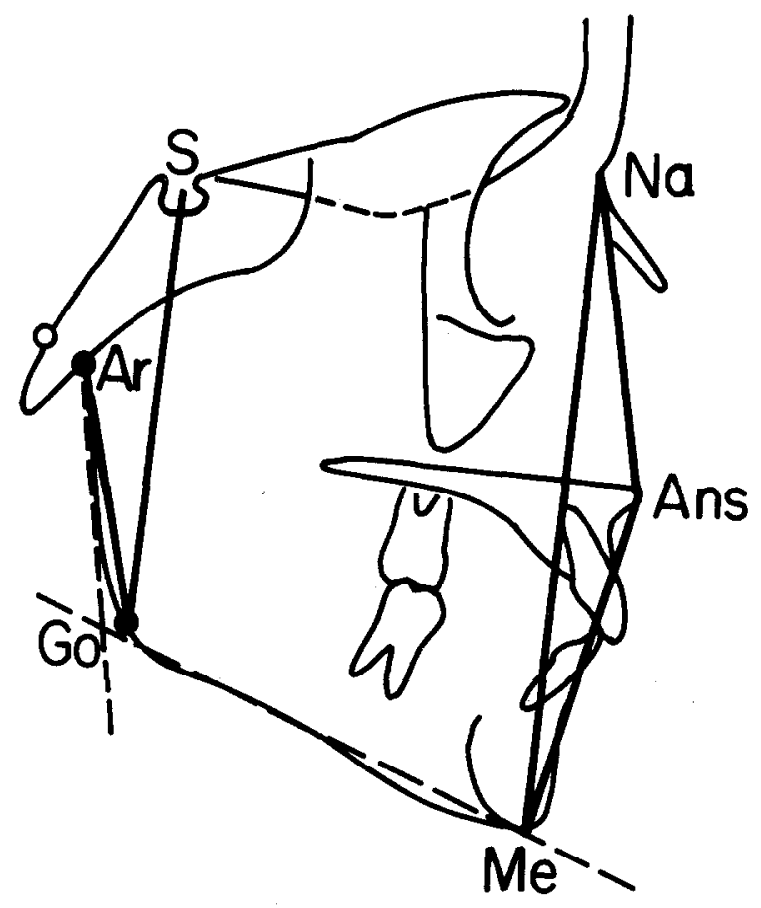

Fig. 1. Cephalometric landmarks used to construct the five linear measurements analyzed in this study. Mandibular planes used to establish gonion are indicated by broken lines.

Thus, the facial groups represented subjects with either disproportionately large or small lower anterior face heights, subdivided by sex. The means, standard deviations, and ranges of the percentages of lower face height to total anterior face height for each group are listed and compared with data published in the literature (Table I). It should be noted that the selection of these subjects was made on the basis of skeletal relationships without reference to clinical evaluation of the occlusion per se. The values relating to lower face height of the subjects used in this study, as shown in Table I, exceed the values determined for characterizing skeletal open- and deep-bite subjects by a number of investigators..$^{9,11,21}$

For the purpose of selecting the subjects, a single radiograph was used to determine the relative lower face height for each person. These radiographs were taken at approximately 15 years of age for male subjects and 13 years 6 months of age for female subjects. These specific ages were selected in order to approximate the stage of development beyond the peak year of the adolescent growth spurt. $29-31$

From an analysis of the literature,,$^{1-3,5,11,21}$ it was ascertained that five specific linear cephalometric dimensions were the best discriminators of the subjects

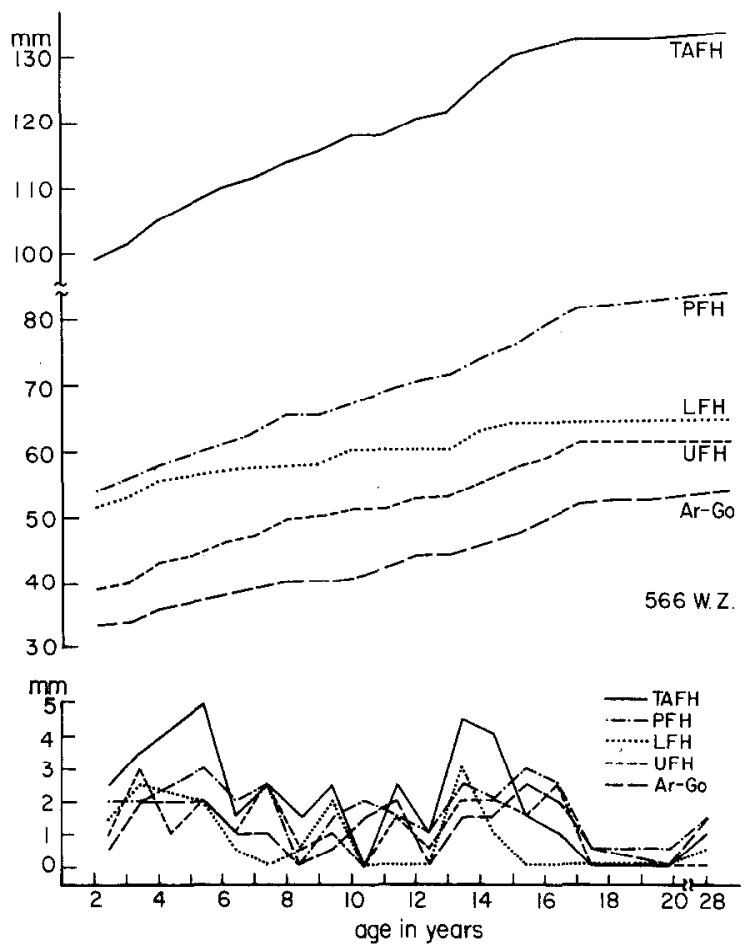

Fig. 2. Absolute and incremental curves for five height measurements of the face plotted for single subject.

with vertical facial dysplasia. These linear distances can be defined as follows (Fig. 1):

1. Morphologic face height $(\mathrm{TAFH})=$ nasionmenton

2. Upper anterior face height $(\mathrm{UAFH})=$ nasionanterior nasal spine

3. Lower anterior face height $(\mathrm{LAFH})=$ anterior nasal spine-menton

4. Posterior face height $(\mathrm{TPFH})=$ sella-gonion

5. Ramal height $(\mathrm{RH})=$ articulare-gonion

\section{Analysis}

The data were analyzed by graphic and statistical methods in order to present individual and group findings. For each subject absolute and incremental curves were constructed for the five dimensions (Fig. 2). These curves were used as a basis for plotting the absolute curves of growth for each of the five dimensions for each of the four groups. For those subjects with missing data at any age, a polynomial regression was calculated for each of the five measurements in order to obtain an interpolated value.

Descriptive statistics for each group at each age were calculated for yearly absolute values of each of the five dimensions between 4 and 18 years. Analyses 
Table II. Descriptive statistics on the absolute values $(\mathrm{mm})$ for three anterior facial dimensions from 4 to 18 years of age for the four groups

\begin{tabular}{|c|c|c|c|c|c|c|c|c|}
\hline \multirow{2}{*}{$\begin{array}{c}\text { Age } \\
(y r)\end{array}$} & \multicolumn{2}{|c|}{ Mate open bite } & \multicolumn{2}{|c|}{ Male deep bite } & \multicolumn{2}{|c|}{ Female open bite } & \multicolumn{2}{|c|}{ Female deep bite } \\
\hline & Mean & $S D$ & Mean & $S D$ & Mean & $S D$ & Mean & $S D$ \\
\hline \multicolumn{9}{|c|}{ Total anterior face height } \\
\hline 4 & 91.3 & 3.3 & 93.3 & 6.2 & 88.3 & 3.2 & 85.1 & 5.9 \\
\hline 6 & 99.8 & 3.1 & 96.7 & 5.5 & 95.0 & 2.6 & 91.5 & 4.5 \\
\hline 9 & 107.1 & 3.5 & 103.3 & 5.4 & 103.3 & 3.9 & 100.1 & 4.2 \\
\hline 12 & 114.3 & 3.6 & 108.9 & 5.7 & 110.4 & 4.0 & 106.7 & 4.2 \\
\hline 15 & 122.2 & 5.6 & 115.9 & 5.6 & 114.0 & 4.4 & 111.7 & 4.9 \\
\hline 18 & 128.6 & 5.8 & 123.9 & 5.3 & 117.1 & 5.0 & 113.7 & 5.9 \\
\hline \multicolumn{9}{|c|}{ Upper anterior face height } \\
\hline 4 & 36.4 & 1.5 & 40.5 & 2.7 & 36.5 & 2.2 & 35.3 & 2.9 \\
\hline 6 & 40.4 & 1.5 & 43.1 & 2.5 & 39.4 & 2.5 & 40.1 & 2.6 \\
\hline 9 & 44.3 & 1.7 & 47.8 & 2.3 & 42.9 & 3.4 & 45.8 & 2.9 \\
\hline 12 & 47.8 & 2.5 & 51.0 & 2.3 & 46.8 & 3.2 & 49.3 & 2.9 \\
\hline 15 & 50.4 & 2.9 & 54.5 & 2.6 & 48.0 & 4.1 & 51.2 & 2.5 \\
\hline 18 & 52.3 & 2.9 & 58.0 & 2.4 & 48.6 & 4.6 & 51.4 & 2.9 \\
\hline \multicolumn{9}{|c|}{ Lower anterior face height } \\
\hline 4 & 57.4 & 2.7 & 49.9 & 9.7 & 53.9 & 2.3 & 51.0 & 3.2 \\
\hline 6 & 62.1 & 2.9 & 52.5 & 7.8 & 56.7 & 3.1 & 53.2 & 2.7 \\
\hline 9 & 65.0 & 2.5 & 56.6 & 3.5 & 61.3 & 2.4 & 55.3 & 1.9 \\
\hline 12 & 68.7 & 2.0 & 59.2 & 3.9 & 64.5 & 2.8 & 58.1 & 2.5 \\
\hline 15 & 73.9 & 4.2 & 62.6 & 4.0 & 67.9 & 3.4 & 61.2 & 3.1 \\
\hline 18 & 78.7 & 5.4 & 66.4 & 4.7 & 70.8 & 4.1 & 63.2 & 3.2 \\
\hline
\end{tabular}

Table III. Descriptive statistics on the absolute values $(\mathrm{mm})$ for two posterior facial dimensions from 4 to 18 years of age for the four groups

\begin{tabular}{|c|c|c|c|c|c|c|c|c|}
\hline \multirow{2}{*}{$\begin{array}{c}\text { Age } \\
(y r)\end{array}$} & \multicolumn{2}{|c|}{ Male open bite } & \multicolumn{2}{|c|}{ Male deep bite } & \multicolumn{2}{|c|}{ Female open bite } & \multicolumn{2}{|c|}{ Female deep bite } \\
\hline & Mean & $S D$ & Mean & $S D$ & Mean & $S D$ & Mean & $S D$ \\
\hline \multicolumn{9}{|c|}{ Total posterior facial height } \\
\hline 4 & 55.4 & 1.6 & 56.2 & 2.8 & 53.1 & 2.8 & 52.7 & 6.1 \\
\hline 6 & 61.2 & 1.8 & 60.3 & 2.9 & 57.8 & 1.9 & 58.7 & 5.9 \\
\hline 9 & 66.3 & 2.8 & 65.5 & 2.5 & 64.2 & 2.8 & 63.9 & 5.6 \\
\hline 12 & 71.4 & 2.4 & 70.1 & 3.1 & 68.9 & 3.3 & 69.2 & 5.3 \\
\hline 15 & 77.0 & 3.7 & 75.7 & 4.1 & 72.8 & 3.8 & 74.0 & 5.3 \\
\hline 18 & 81.6 & 4.6 & 82.5 & 4.8 & 76.0 & 5.9 & 76.3 & 4.9 \\
\hline \multicolumn{9}{|c|}{ Ramal height } \\
\hline 4 & 33.1 & 2.7 & 34.2 & 2.2 & 30.8 & 1.9 & 32.6 & 4.9 \\
\hline 6 & 36.8 & 2.5 & 36.7 & 2.7 & 33.6 & 1.4 & 35.9 & 3.9 \\
\hline 9 & 39.1 & 2.2 & 38.7 & 2.6 & 36.5 & 2.0 & 38.5 & 3.9 \\
\hline 12 & 42.8 & 1.9 & 41.7 & 2.9 & 40.8 & 3.5 & 41.2 & 3.5 \\
\hline 15 & 46.3 & 2.6 & 45.2 & 2.9 & 43.3 & 2.9 & 45.1 & 3.9 \\
\hline 18 & 50.1 & 2.8 & 50.4 & 3.7 & 46.0 & 4.8 & 46.9 & 4.1 \\
\hline
\end{tabular}

of variance were performed to test for the overall effects of age, vertical proportions (open bite or deep bite), sex, and the interaction of these factors. Pairwise comparisons were made between open-bite and deep-bite groups within each sex (MO-MD, FO-FD) and between sexes (MO-FO, MD-FD), and their combination of counterpart groups (MO-FD, MD-FO). The orthogonal contrasts between open bites and deep bites in male and female subjects were determined. The level of significance for each comparison was predetermined at an alpha level of 0.05 . The $F$ test, using the Bonferroni procedure for pairwise comparison, was applied to determine the significance of difference between the mean values. 


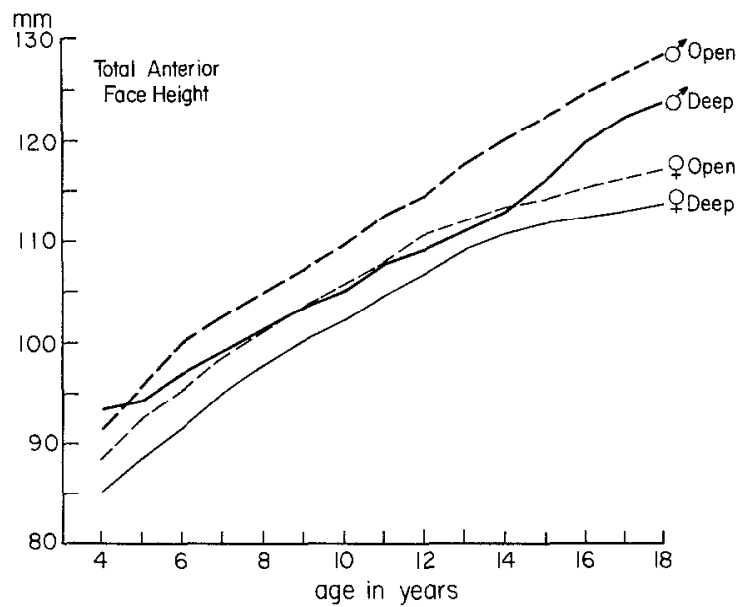

Fig. 3. Mean absolute curves of growth for total anterior face height for open-bite and deep-bite subjects segregated by sex.

The results of this study will be presented in four sections: (1) typological differences in the cumulative growth curves, (2) typological differences in facial proportions over time, (3) percentile attainments in the total anterior face height and its components, and (4) relationship of typological differences to the adolescent growth spurt.

\section{RESULTS}

The F test, using the Bonferroni procedure for pairwise comparison, indicated that the lower face height taken as a percentage of total face height discriminated the open-bite and deep-bite subjects within each sex $(P<0.0001)$. However, comparison of the sexes within each group showed no significant differences. These findings confirm the appropriate use of percentage of lower anterior face height as the criterion to select the subjects representing the open-bite and the deep-bite categories. Descriptive statistics on the absolute values for five facial dimensions are reported in Tables II and III.

\section{Typological differences in the cumulative curves of growth}

Total anterior face height. Graphic representation of growth curves for anterior face height for the openand deep-bite groups shows the classical pattern of sexual dimorphism in the earlier attainment of a plateau in female growth curves and the greater absolute values at each chronologic age for the male subjects within each facial type (Fig. 3). Within each sex typological differences were clearly cvident in the greater dimensional attainment of the open-bite subjects at each chronologic age, with the minor exception for the deep-bite

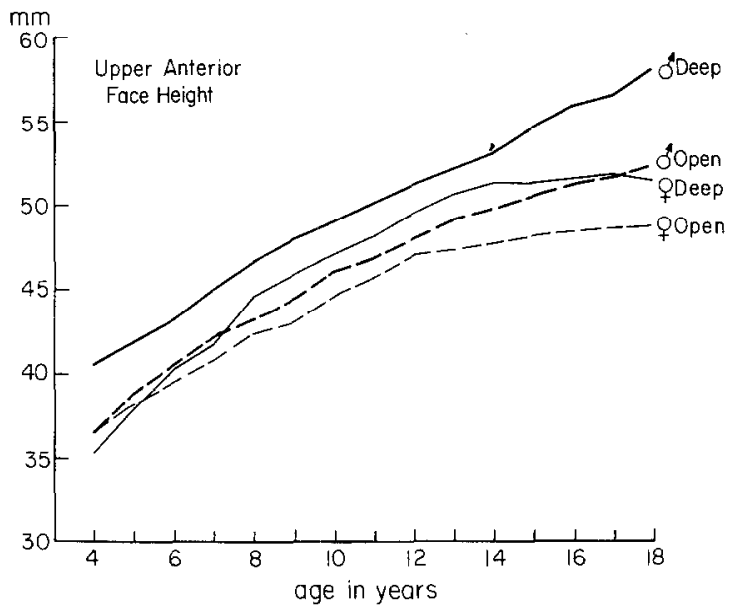

Fig. 4. Mean absolute curves of growth for upper anterior face height for open-bite and deep-bite subjects segregated by sex.

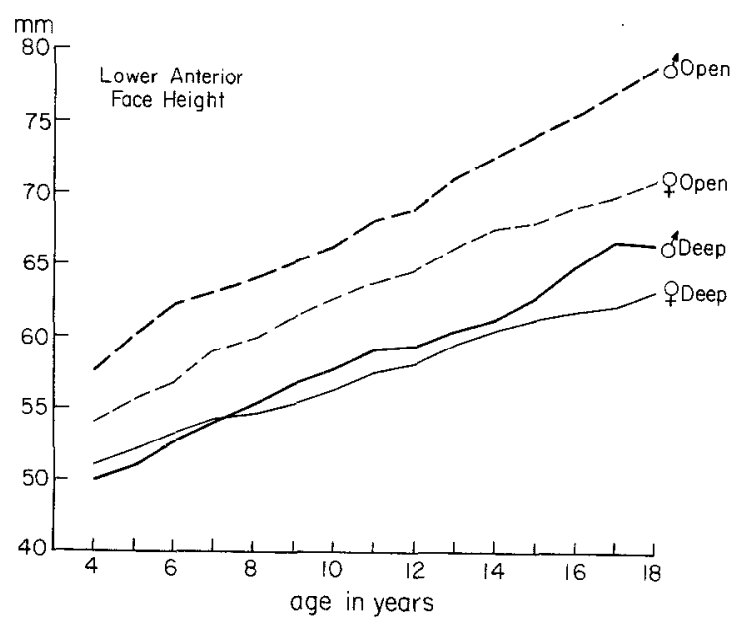

Fig. 5. Mean absolute curves of growth for lower anterior face height for open-bite and deep-bite subjects segregated by sex.

male subjects during the short period from 4 to 5 years of age. The male deep-bite and the female open-bite curves were congruent until sexual dimorphism was manifested at 11 years of age. Until the initiation of the prepubertal spurt in the male subjects at approximately 14 years of age, values for the female subjects' total face height actually exceeded those for the male subjects. Subsequently, the corresponding curves were widely separated. The area of overlap at puberty in which the female open-bite subjects exceeded the values for the deep-bite male subjects suggests that typological factors were greater than normal sex differences. This observation is supported by a comparison of the values for the male open-bite and the female open-bite subjects. Viewed graphically, it appeared that typological differences were established as early as 6 years of age, 


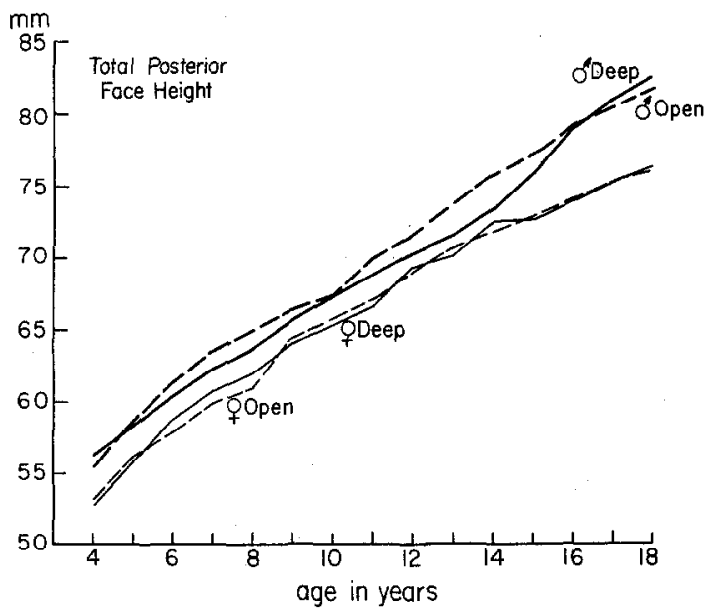

Fig. 6. Mean absolute curves of growth for total posterior face height for open-bite and deep-bite subjects segregated by sex.

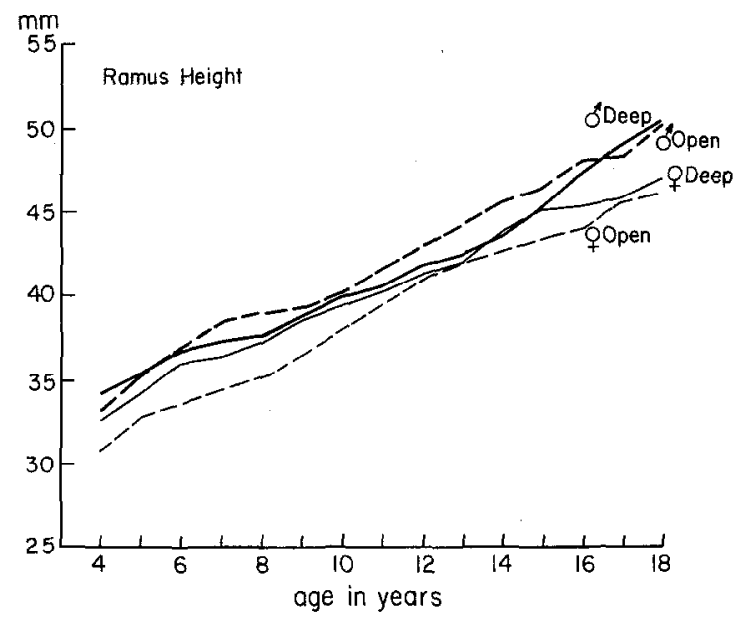

Fig. 7. Mean absolute curves of growth for ramus height for open-bite and deep-bite subjects segregated by sex.

even before the eruption of the permanent dentition and long before adolescence.

Upper anterior face height (Fig. 4). Attainment of size increases of upper face height is quite different from that observed for total anterior face height. In both sexes the deep-bite groups were characterized by larger UAFH dimensions than the open-bite subjects. The curves of both sexes for deep-bite subjects ran parallel from 8 to 14 years of age. At this age sexual dimorphism resulted in a divergence. The relative positioning of the mean curves demonstrated that upper face height was larger for deep-bite groups in both sexes.

The mean cumulative growth curve for the female deep-bite subjects was positioned halfway between those of the male deep-bite and the male open-bite

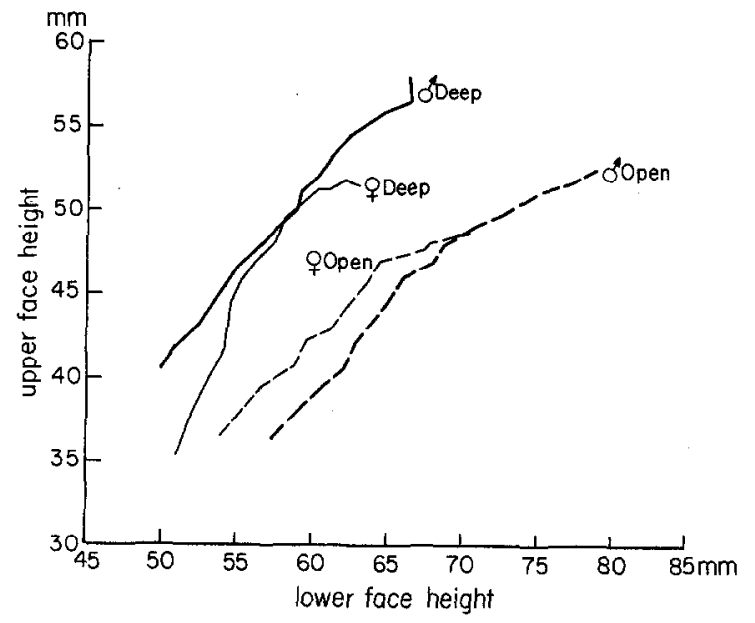

Fig. 8. Comparison of the ratios of upper face height and lower face height by sex and facial type.

curves from 8 to approximately 17 years of age. The intermediate position of the female deep-bite curve was caused by a pronounced acceleration approximately at 8 years of age. At 18 years of age, however, the female deep-bite and the male open-bite subjects were virtually indistinguishable dimensionally due to the early attainment of the plateau in the female subjects and the later growth of the male subjects.

Lower anterior face height (Fig. 5). The absolute growth curves for lower anterior face height showed a typological difference similar to TAFH between open bite and deep bite in both sexes. This difference was so pronounced that the female open-bite values well exceeded the corresponding values for male deepbite subjects. In this sense typological differences negated sexual dimorphism. Thus, the pattern observed for growth in the lower anterior face height represented a complete reversal from that described for upper anterior face height and facial types provided a better discriminator for growth attainments than gender.

Total posterior face height (Fig. 6). In contrast to the anterior facial dimensions, the growth curves for total posterior face were tightly clustered and therefore not segregated by type for either sex. The greater values for both male groups and the divergence of the curves at adolescence reflected sexual dimorphism in magnitude of attainments.

Ramal height (Fig. 7). The growth curves for ramal height were clustered fairly well. This was not surprising since ramal height is a major contributor to posterior facial height. No typological pattern was discernible. No significant differences were found for TPFH (total posterior face height) and RH (ramal height) by facial type within the sexes (Table IV). 
Table IV. Bonferroni test of significance differences ( $P$ values) between open- and deep-bite groups for three anterior dimensions of the face

\begin{tabular}{|c|c|c|c|c|c|c|}
\hline Age & $M O-M D$ & $F O-F D$ & $M O-F O$ & $M D-F D$ & $M O-F D$ & $M D-F O$ \\
\hline \multicolumn{7}{|l|}{4 years } \\
\hline TAFH & NS & NS & NS & $* * *$ & * & $*$ \\
\hline UAFH & $* * *$ & NS & NS & $* * * *$ & $*$ & $* * *$ \\
\hline LAFH & $* * *$ & NS & NS & NS & $* * * *$ & NS \\
\hline \multicolumn{7}{|l|}{6 years } \\
\hline TAFH & NS & NS & $*$ & $* *$ & $* * * *$ & NS \\
\hline UAFH & $*$ & NS & $*$ & $*$ & NS & $* * *$ \\
\hline LAFH & $* * * *$ & NS & * & NS & $* * * *$ & $* *$ \\
\hline \multicolumn{7}{|l|}{9 years } \\
\hline TAFH & NS & NS & NS & NS & $* * *$ & NS \\
\hline UAFH & $*$ & $*$ & NS & NS & NS & $* * *$ \\
\hline LAFH & $* * * *$ & $* * * *$ & $* * *$ & NS & $* * * *$ & $* *$ \\
\hline \multicolumn{7}{|l|}{12 years } \\
\hline TAFH & * & NS & NS & NS & $* * *$ & NS \\
\hline UAFH & $*$ & $*$ & NS & NS & NS & $* * *$ \\
\hline LAFH & $* * * *$ & $* * * *$ & $* * *$ & NS & $* * * *$ & $* *$ \\
\hline \multicolumn{7}{|l|}{15 years } \\
\hline TAFH & $*$ & NS & $* * *$ & NS & $* * * *$ & NS \\
\hline UAFH & $*$ & $*$ & NS & $*$ & NS & $* * * *$ \\
\hline LAFH & $* * * * *$ & $* * * *$ & $* * *$ & NS & $* * * * *$ & $* *$ \\
\hline \multicolumn{7}{|l|}{18 years } \\
\hline TAFH & NS & NS & $* * * *$ & $* * * *$ & $* * * *$ & $*$ \\
\hline UAFH & $* * * *$ & NS & $*$ & $* * * *$ & NS & $* * * *$ \\
\hline LAFH & $* * * *$ & $* * *$ & $* * *$ & $*$ & $* * *$ & $*$ \\
\hline
\end{tabular}

$\mathrm{MO}=$ Male open bite; $\mathrm{MD}=$ male deep bite; $\mathrm{FO}=$ female open bite; $\mathrm{FD}=$ female deep bite

${ }^{*} P<0.05$. ${ }^{* * P}<0.01 .{ }^{* * * P}<0.001 .{ }^{* * *} P<0.0001$.

\section{Typological differences in facial proportions}

To further demonstrate typological and sex differences, comparisons of the relative dimensional increase were evaluated by plotting the absolute size of facial dimensions against corresponding ages (Figs. 8 through 14).

Upper anterior face height versus lower anterior face height (Fig. 8). When the absolute dimensions for upper face height were plotted against those of lower face height for the four groups, the curves were clearly segregated by facial type in both sexes. The slope of the curves for the deep-bite groups indicated that the upper face height was growing more rapidly. In contrast, the slope of the curves for the open-bite groups showed the lower face height to be greater. This plotting of the raw data places the focus upon typological differences and deemphasizes sexual dimorphism. The two female group curves fell between the two male curves. The deep-bite male subjects were ahead of the deep-bite female subjects and the open-bite female subjects were ahead of the open-bitc male subjects, thus diminishing sex differences.

Lower anterior face height versus posterior face height (Fig. 12). Plotting of the dimensions for lower anterior face height against total posterior face height clearly segregated the subjects in terms of facial type. As might be anticipated, the relative positions of the four curves represented a direct reversal from the order obtained on the basis of upper face height plotted against total posterior face height (Fig. 11). The slope of the curves showed a rcmarkably greater relative increase in lower face height in open-bite groups as opposed to the deep-bite subjects.

After 7 years of age, the deep-bite curves for both male and female subjects were congruent, and this relationship persisted throughout the growing period. Conversely, in the open-bite groups, the sex differences were established at an earlier age (even before the beginning of the mixed dentition) and were maintained throughout the growing period.

Upper anterior face height versus ramal height (Fig. 13). As anticipated from earlier comparisons, the plotting of upper face height against ramus height resulted in a pattern of distribution of the curves that was comparable to that obtained when upper anterior face height was plotted against posterior face height. 


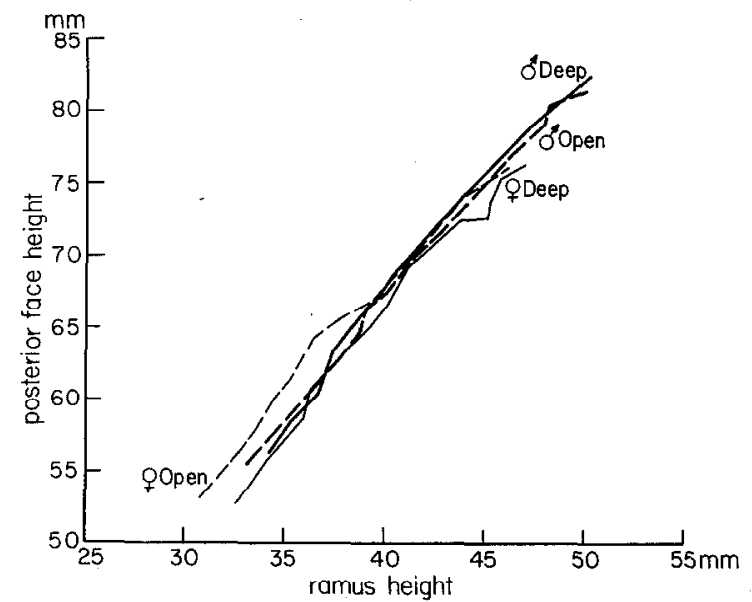

Fig. 9. Comparison of the ratios of posterior face height and ramus height by sex and facial typology. The four curves are tightly clustered (with the exception of an initial segment for the deep-bite female subjects) and can almost be represented by a single curve. The concordance indicates that the growth of these dimensions is similar and nondiscriminating.

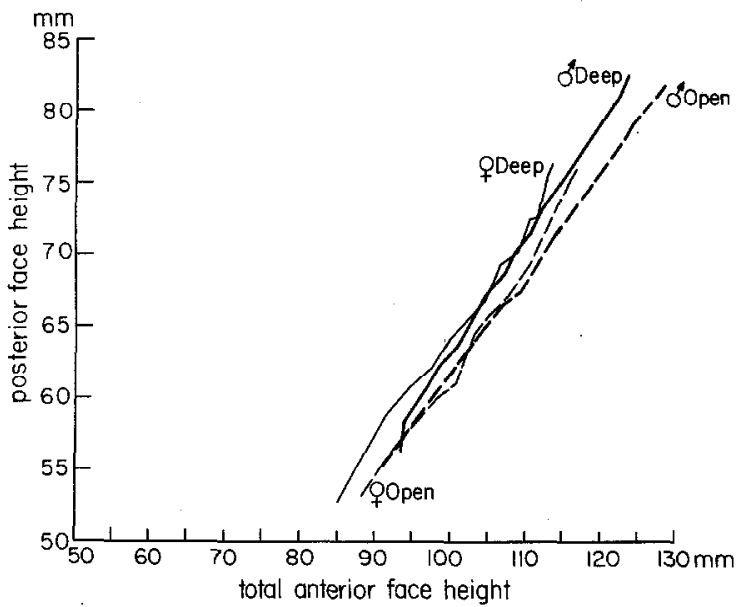

Fig. 10. Comparison of the ratios of posterior face height and total anterior face height by sex and facial type. The four curves are remarkably parallel and are closely approximate in distance. Graphicaily, there is a slight suggestion of typological difference between deep-bite and open-bite groups, with the total anterior face height somewhat decreased in the deep-bite groups relative to total posterior face height.

A greater relative increase in upper face height was evident in the deep-bite group as opposed to open-bite subjects. Again, sexual dimorphism was submerged relative to the differences in facial type. The typological differences became increasingly more apparent after 8 years of age. The same phenomenon was observed when upper anterior face height was plotted against total posterior face height.

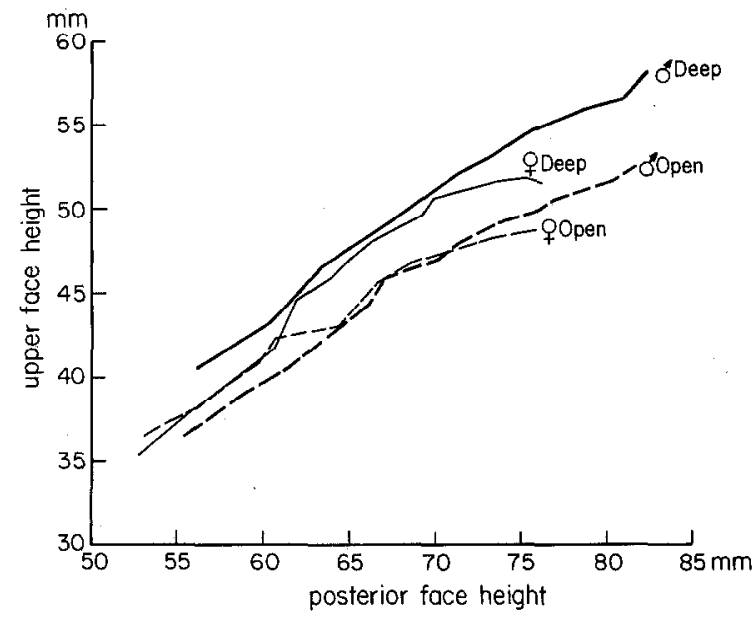

Fig. 11. Comparison of the ratios of upper face height and posterior face height by sex and facial type. In this comparison there is a distinct difference between the open- and deep-bite curves. It is interesting to note that the female groups start together but become segregated by 8 years of age, while the male groups are clearly segregated throughout the progression of growth from 3 to 18 years of age.

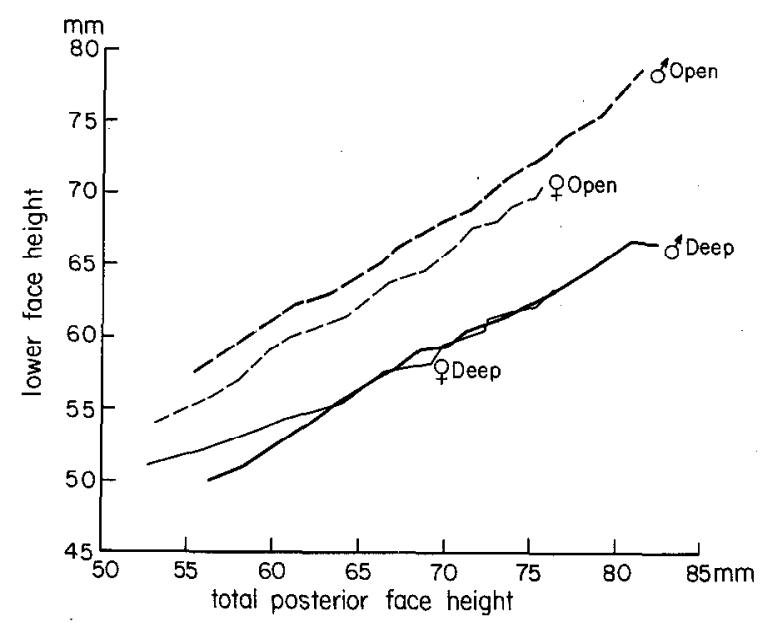

Fig. 12. Comparison of the ratios of lower face height and total posterior face height by sex and facial type.

\section{Percentile attainments in the total anterior face height and its components}

In this section the values for total anterior face height have been converted into percentile curves showing the percentage of attainment at each chronologic age using the absolute size at 18 years of age as $100 \%$ attainment. In addition, the absolute values of upper and lower anterior face heights have been calculated as the percentage of total anterior face height at cach chronologic age.

Total anterior face height (Fig. 15). Plots of the 


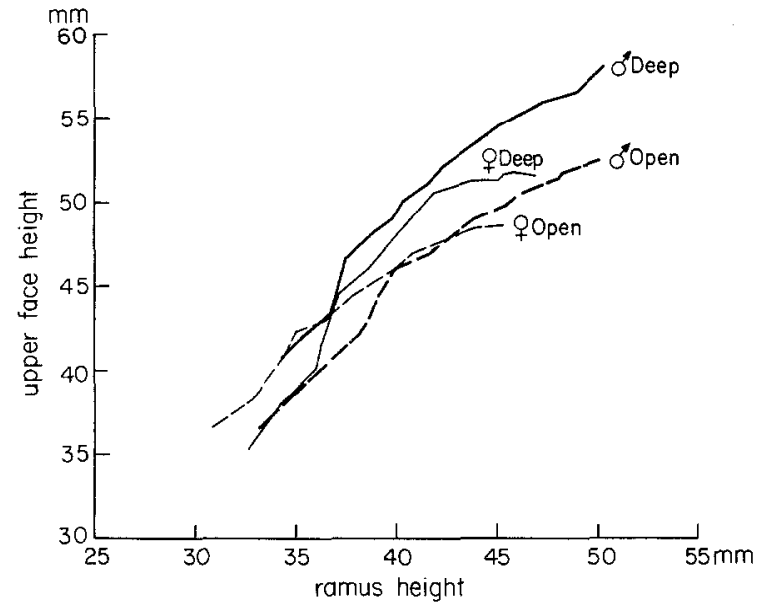

Fig. 13. Comparison of the ratios of upper face height and ramus height by sex and facial type.

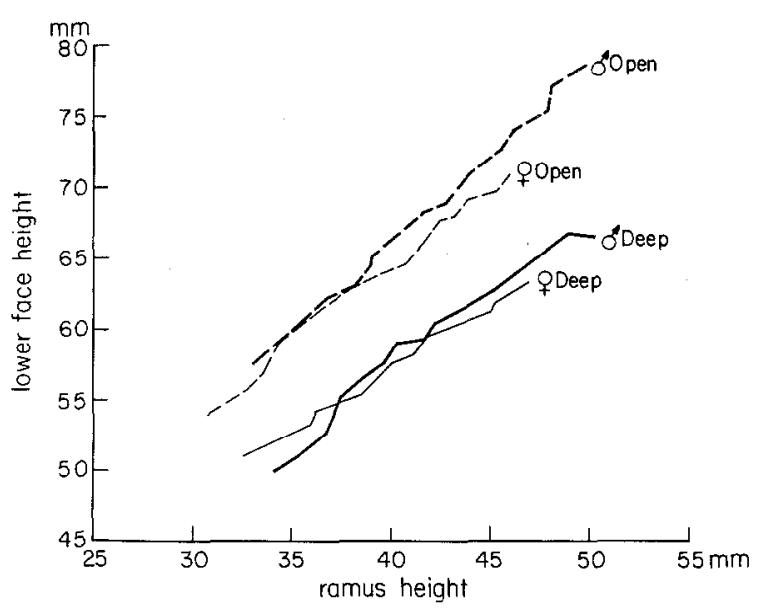

Fig. 14. Comparison of the ratios of lower face height and ramus height by sex and facial type. The four curves clearly segregate the four groups by facial type and essentially eliminate the effects of sexual dimorphism. As would be expected, the positional sequence of the curves in the graph is reversed from that of the plotting for upper anterior face height.

percentile curves for total anterior face height emphasized the characteristics of sexual dimorphism that are frequently observed for many dimensions of the body. At each chronologic age, the two female groups were closer to their ultimate size (here taken at 18 years) than the male subjects. The remarkable concordance between the two female curves essentially eliminated all typological differences.

In the male subjects, however, some typological difference was suggested at adolescence. The open-bite males appeared to reach adolescence at an carlicr age and exceeded the values for the deep-bite males from 11 years to 16 years of age. The more slowly growing

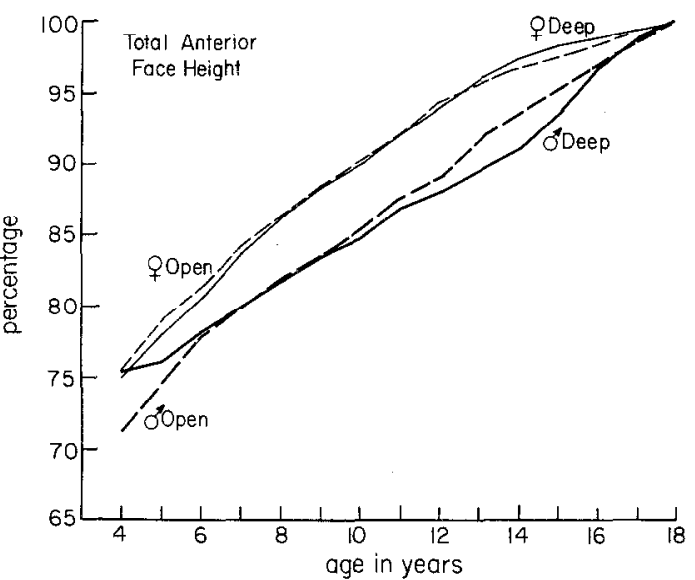

Fig. 15. Percentile curves of growth for total anterior face height using terminal value at 18 years as $100 \%$.

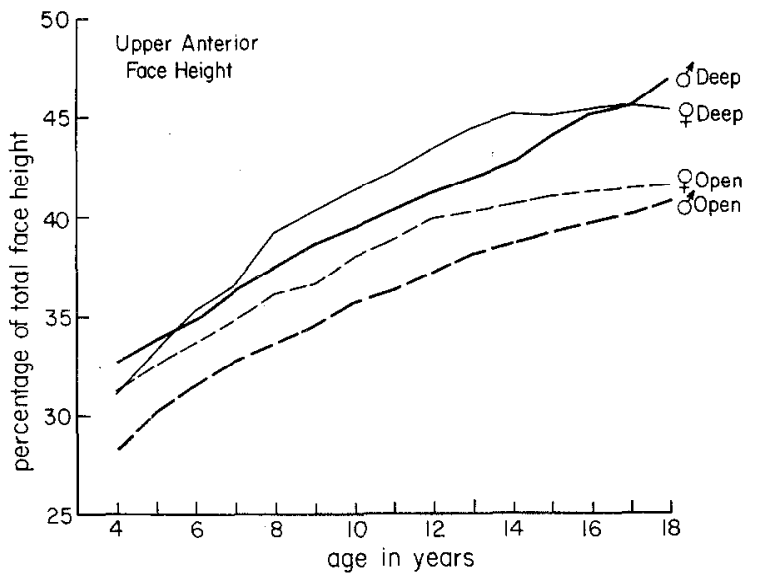

Fig. 16. Curve of growth of upper anterior face height taken as a percentage of total face height.

deep-bite males exhibited the classic sigmoid curve configuration at adolescence, with a pronounced spurt of growth. Nevertheless, analysis of variance failed to demonstrate any significant differences between the male open-bite and deep-bite values (Table V). This test indicated that for total anterior face height, there are no significant differences between facial types. Sex differences were highly significant in both intra- and intertypological comparisons.

Upper anterior face height taken as a percentage of total face height (Fig. 16). The sequential change in proportions at different ages is demonstrated by a comparison of the relative size of the upper face in the openbite and deep-bite groups.

The curves for each facial type showed differences in magnitude and relative rates of growth. The relative magnitude of upper face height was increased in deep- 
Table V. Bonferroni test for pairwise comparisons of sex differences and facial types for anterior face height as a percentage of total anterior face height at 18 years

\begin{tabular}{r|c|c|c|c|c|c}
\hline $\begin{array}{c}\text { Age } \\
(y r)\end{array}$ & $M O-M D$ & $F O-F D$ & $M O-F O$ & $M D-F D$ & $M O-F D$ & $M D-F O$ \\
\hline 4 & $*$ & NS & $*$ & NS & $*$ & NS \\
6 & NS & NS & $*$ & NS & $*$ & $*$ \\
9 & NS & NS & $* * *$ & $* * * * *$ & $* * *$ \\
12 & NS & NS & $* * * * * * *$ & $* * *$ \\
15 & NS & NS & $* *$ & $* * * * * *$ & $* * *$ \\
\hline
\end{tabular}

${ }^{*} P<0.05 .{ }^{* *} P<0.01 .{ }^{* * *} P<0.001 .{ }^{* * * * P}<0.0001$.

Table Vl. Bonferroni test for pairwise comparisons of sex differences and facial types: Upper face height/total face height based upon percentage attainments at different chronologic ages of adult size at 18 years

\begin{tabular}{|c|c|c|c|c|c|c|}
\hline $\begin{array}{l}\text { Age } \\
(y r)\end{array}$ & $M O-M D$ & $F O-F D$ & $M O-F O$ & $M D-F D$ & $M O-F D$ & $M D-F O$ \\
\hline 4 & $* * * *$ & NS & $* *$ & NS & $* *$ & NS \\
\hline 6 & $* * *$ & $*$ & $* *$ & NS & $* * * *$ & NS \\
\hline 9 & $* * * *$ & $* * * *$ & $*$ & $*$ & $* * * *$ & * \\
\hline 12 & $* * * *$ & $* * *$ & $* *$ & $* *$ & $* * * *$ & NS \\
\hline 15 & $* * * *$ & $* * *$ & NS & NS & $* * * *$ & $* *$ \\
\hline 18 & $* * * *$ & $* *$ & NS & NS & $* * *$ & $* * * *$ \\
\hline
\end{tabular}

${ }^{*} P<0.05 .{ }^{* *} P<0.01 .{ }^{* * *} P<0.001 .{ }^{* * * *} P<0.0001$.

bite subjects of both sexes as compared with the openbite groups. For most of its length, the male deep-bite curve was positioned halfway between the female deepbite and female open-bite curves. Thus, the typological difference has blurred the sexual dimorphism. The patterns of the growth curves were established at a fairly early age and maintained during the progression of growth.

At 4 years of age, the relative size of upper face height in the male deep-bite group was significantly greater (Table VI) than in the male open-bite subjects. This difference persisted until 14 years of age when the adolescent growth spurt in the deep-bite group actually increased the difference between the two groups. When the upper face height was taken as percentage of total anterior face height, then it must be noted that the deepbite male subjects attained a value at 12 years of age that exceeded the ultimate value of the open-bite male subjects at adulthood.

Statistical analysis of upper face height taken as percentage of total anterior face height (Table VI) indicated that highly significant diffcrences cxist between the facial types. The Bonferroni test further supported the interpretation of the graphic data that typological differences tended to override sexual dimorphism.

Lower anterior face height taken as a percentage of total face height. Fig. 17 demonstrates that the growth behavior of lower anterior facial height is almost the reciprocal of upper face height. The sequence of the curves is reversed, while the distances between the curves remain essentially comparable. Lower anterior face height in the open-bite male subjects achieved a percentage of total anterior face height by 12 years of age. This exceeded the value obtained by the deep-bite male subjects at adulthood.

The test for paired comparisons showed highly significant differences betwecn facial types within both sexes at 6 years of age in the male open- and deep-bite subjects, and at 9 years of age for the female subjects (Table VII).

\section{Relationship of typological differences to the adolescent growth spurt}

The mean values and standard deviations for the five facial dimensions in each of the four groups are shown in Table VIII and are depicted graphically in Fig. 18, with the year of maximum growth of the five dimensions studied documented for each of the four groups.

The clustering of the data is suggestive of a gradient in the timing of the pubertal spurt, with the earliest spurts occurring in the female open-bite subjects fol- 


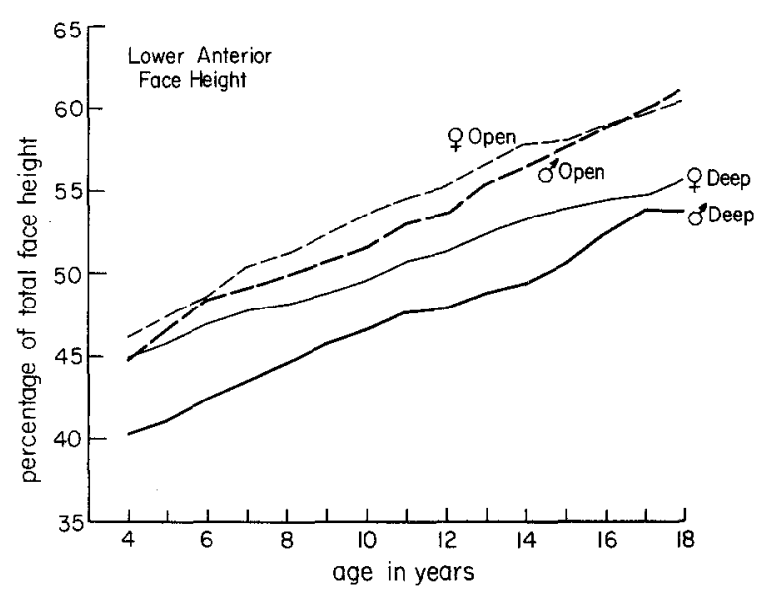

Fig. 17. Curve of growth of lower anterior face height taken as a percentage of total face height.

lowed in order by the female deep-bite, male open-bite, and finally the male deep-bite subjects. The Bonferroni correction for pairwise comparison, however, showed a significant difference only for the measurement of total posterior face height between the male deep-bite and male open-bite groups (Table IX). The MD-FO column in Table IX clearly demonstrates that extremes of facial type override sexual dimorphism in terms of timing of maximum growth.

\section{DISCUSSION}

The data reported in this study are discussed here with respect to:

1. The significance of facial growth patterns and their influence in the determination of facial form

2. Facial form and sex differences in the timing of the adolescent growth spurt

3. Clinical implications

\section{Growth patterns}

Many previous efforts have been made to characterize the differences in vertical facial types and to discriminate the two extremes. However, apart from a description of observed morphologic differences, there is a lack of understanding concerning the dynamics that typify the development of vertical dysplasias.

The evidence presented in this study indicates that the patterns of development of the open- and deep-bite faces, as demonstrated by both the cumulative and the percentile growth curves, are established at an early age. These divergent patterns are evident even before the eruption of the permanent teeth and long before the adolescent growth spurt.

It is important to note that the dimensions of total anterior face height, upper face height, and lower face

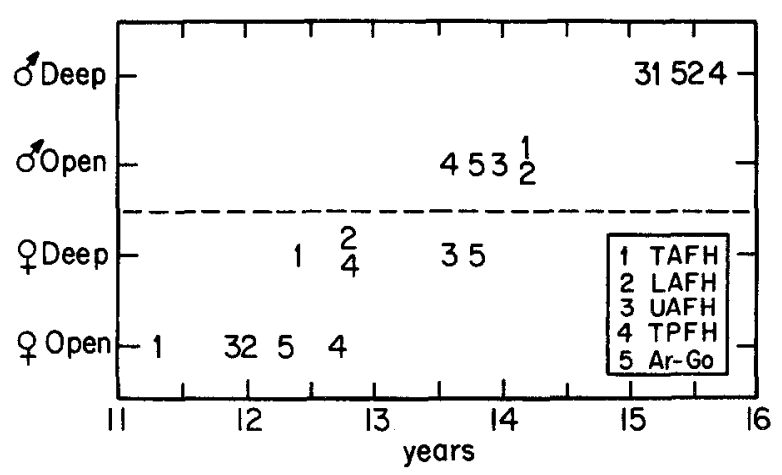

Fig. 18. Schematic representation showing the timing of the peak of the pubertal spurts for the five dimensions.

height demonstrate remarkable typological differences that diminished the effects of sexual dimorphism. Further, the magnitude of the dimensional differences between the open-bite and deep-bite configurations becomes progressively accentuated during adolescence. These observations point to the significance of differential growth of the upper and lower components of the face. Although vertical facial type was definable early and remains characteristic for the individual, deep- and open-bite patients actually scem to grow differently up to their attained mature size.

The association of facial type with dimensional attainments is illustrated by the fact that upper and lower face heights have an inverse growth relationship. In the deep-bite subjects, upper face height is increased, while in the open bite subjects the lower face height is increased. As a result these proportional shifts produce a typological size gradient that (even) overrides sexual dimorphism.

The fact that the curves for posterior face height and ramal height do not discriminate between the two typological groups in either sex suggests that the differences reside in the anterior segments of the face. The same is not true of the posterior dimensions. Thus, the fundamental difference between the open- and deepbite faces is found in the anterior segments of the face, rather than in variations of ramal height or total posterior face height.

These findings are at variance with the prevailing concepts expressed in much of the literature, which emphasize the role of the posterior dimension in the etiology of vertical dysplasias. Björk ${ }^{5}$ demonstrated $^{2}$ schematically that open bite is associated with a large ramus, while Sassouni and Nanda, ${ }^{10}$ and Schudy ${ }^{2}$ rcported that open bite is associated with deficient ramal height. These findings are in contrast to $\mathrm{Wylie}^{4}$ and Fields and associates ${ }^{21}$ who reported a comparable posterior face height in open bite and deep bite. The pos- 
Table VII. Bonferroni test for pairwise comparisons of sex differences and facial types: Lower face height/total face height based upon percentage attainments at different chronologic ages of adult size at 18 years

\begin{tabular}{|c|c|c|c|c|c|c|}
\hline $\begin{array}{l}\text { Age } \\
(y r)\end{array}$ & $M O-M D$ & $F O-F D$ & $M O-F O$ & $M D-F D$ & $M O-F D$ & $M D-F O$ \\
\hline 4 & NS & NS & NS & $*$ & NS & $*$ \\
\hline 6 & $* *$ & NS & NS & $*$ & NS & $* *$ \\
\hline 9 & $* * *$ & $* *$ & NS & $* * *$ & NS & $* * * *$ \\
\hline 12 & $* * * *$ & $* * *$ & NS & $* * *$ & $*$ & $* * * *$ \\
\hline 15 & $* * * *$ & *k* & NS & **** & *末* & $* * * *$ \\
\hline 18 & $* * * *$ & $* * * *$ & NS & $*$ & $* * * *$ & $* * * *$ \\
\hline
\end{tabular}

$* P<0.05 .{ }^{* * P} P<0.01 . * * * P<0.001 . * * * * P<0.0001$.

Table VIII. Means and standard deviations for timing of adolescent spurt for five dimensions

\begin{tabular}{l|c|c|c|c|c|c|c|c}
\hline & \multicolumn{3}{c|}{ Female subjects } & \multicolumn{4}{c}{ Male subjects } \\
\cline { 2 - 9 } & \multicolumn{2}{|c|}{ Deep bite } & \multicolumn{2}{c|}{ Open bite } & \multicolumn{2}{c}{ Deep bite } & Open bite \\
\cline { 2 - 9 } Facial dimension & Mean & SD & Mean & SD & Mean & SD & Mean & SD \\
\hline Total anterior height & 12.4 & 1.4 & 11.3 & 1.1 & 15.2 & 1.1 & 14.2 & 1.9 \\
Upper anterior height & 13.6 & 1.2 & 11.9 & 2.5 & 15.1 & 1.7 & 14.0 & 2.0 \\
Lower anterior height & 12.8 & 0.7 & 12.0 & 1.4 & 15.5 & 1.3 & 14.2 & 1.7 \\
Total posterior height & 12.8 & 1.8 & 12.7 & 2.6 & 15.6 & 1.0 & 13.6 & 1.8 \\
Ramus height & 13.8 & 1.1 & 12.3 & 2.3 & 15.4 & 1.0 & 13.8 & 2.1 \\
\hline
\end{tabular}

terior facial dimensions were unaffected in open bites and deep bites as observed in the present study. In the open-bite male and female subjects, the relative deficiency of upper face height observed in this study is in agreement with many authors. ${ }^{8,12,14,22,23}$ However, these findings are not supported by Björk ${ }^{5}$ and Schendel and associates, ${ }^{3}$ who reported that upper vertical height is excessive in open-bite subjects.

A major problem in synthesizing these conflicting views is the fundamentally different source of data. Cross-sectional age-related means cannot readily be compared with the individual variations observed in a longitudinal study.

The individual absolute curves of growth for each of the facial dimensions in this study demonstrate consistency in established facial type throughout the growing period. It is to be noted that the subjects in this study were categorized typologically during the expected adolescent spurt. The view expressed by Bishara and Jakobsen ${ }^{27}$ that $23 \%$ of the subjects categorized at 5 years of age change their pattern of growth is most likely related to the lack of distinctive identifying characteristics to define facial type.

The present study suggests that the differences in vertical facial forms are a result of morphologic differences that are consistently associated with the selec- tive dimensional increases in the segments of the anterior face height. Upper face height grows more relative to lower face height in deep-bite subjects and less in the open-bite subjects. The specific influence of the differential growth in each of the segments of the anterior face modifies the proportions of upper and lower face in each facial type. The strong influences in the developmental patterns of the two facial forms even diminish the expected sexual dimorphism that is expressed in most of the dimensions of the body.

\section{Adolescent growth spurt}

Clearly, boys lag hehind girls in reaching the adolescent growth spurt. The components that comprise anterior and posterior face heights each exhibit a characteristic spurt (or accelerated growth) at adolescence. Orthodontic therapy deals with craniofacial elements and produces overall changes that are additive in nature. Thus, the growth behavior of the parts is of biologic and clinical interest. The four groupings suggest a gradient for the five facial dimensions in which the female open-bitc subjects appear to be the earliest in the timing of the year of maximum growth, followed in succession by the deep-bite female subjects, the open-bite male subjects, and finally the deep-bite male subjects.

The differences in timing between the deep-bite 
Table IX. Bonferroni procedure for pairwise comparisons of year of maximum growth for facial types

\begin{tabular}{c|c|c|c|c|c|c}
\hline $\begin{array}{c}\text { Facial } \\
\text { dimension }\end{array}$ & $M O-M D$ & FO-FD & MO-FO & MD-FD & MO-FD & MD-FO \\
\hline TAFH & NS & NS & $* * *$ & $* * *$ & $*$ & $* * * *$ \\
UAFH & NS & NS & $*$ & NS & NS & $* *$ \\
LAFH & NS & NS & $* *$ & $* * *$ & $*$ & $* *$ \\
TPFH & $*$ & NS & NS & $* *$ & NS & $* *$ \\
ARGO & NS & NS & NS & NS & NS & $* *$ \\
\hline
\end{tabular}

$* P<0.05 . * * P<0.01 . * * * P<0.001 . * * * * P<0.0001$

male subjects and the open-bite female subjects were significantly greater in four of the five dimensions studied. Interestingly, the differences between the male open- and female deep-bite groups were slightly greater than the differences between the two female groups. The difference in timing of the year of maximum growth for total anterior face height between the male deepbite and the female open-bite subjects reached a magnitude of 3.9 years, exceeding the 2.9-year difference between the male and female deep-bite subjects.

\section{Clinical implications}

The observations reported in this study on vertical facial extremes have clinical implications for the timing of orthodontic treatment, the length of the retention period, and the prediction of adult occlusal status during the mixed dentition period. The data suggest that the patterns of anterior vertical facial proportions are established at an early age and maintained during the progression of growth. Consequently, it would appear that it is possible to anticipate the vertical facial development of a child at an early age.

The differences in timing of the pubertal growth spurt of various facial dimensions among the groups suggest that early initiation of orthodontic treatment might be beneficial in persons with relatively large lower face heights because these subjects appear to reach their adolescence at an early age. If the choice of treatment mechanics requires orthopedic modifications of the jaws, then the initiation of treatment is preferable before the adolescent growth spurt. The timing of initiation of treatment in long faces in this sense is similar to that for a Class III malocclusion. It is also conceivable that orthognathic surgical procedures could be performed in persons in this group at an earlier age than is generally suggested at present.

The timing of orthodontic treatment in persons who are characterized by relatively small lower anterior face heights should be delayed until the final positioning of the anterior limits of the denture bases can be determined. It is evident that deep-bite subjects exhibit a prolonged period of facial growth in contrast to openbite subjects. For this reason it is desirable to overtreat the deep-bite subjects and continue retention for a longer period.

Another clinical implication of this study suggests that if the vertical component of lower facial growth is etiologically dominant, then the normal end-to-end relationship of the second primary molars during the mixed dentition stage may not develop toward the proper interdigitation of the first permanent molars in the young adult occlusion. By contrast, persons with small lower anterior face heights may exhibit greater horizontal components, facilitating the normal interdigitation of the molars.

Previous efforts to estimate facial growth have relied essentially on such factors as sex, maturational status, and the rate of maturational progression. In view of the findings presented, it appears that facial growth prediction should also be predicated on the observable facial type. Prediction accuracy may thereby be enhanced.

This investigation contradicts the notion concerning the mechanisms that operate in the development of the two extreme forms of vertical facial types. It often has been assumed that a deficient posterior face height in open-bite subjects causes the posterior teeth to act as a fulcrum, resulting in a backward rotation of the lower jaw and an increase in the lower anterior face height. The corollary of such an assumption would be that in deep-bite subjects excessive posterior face height permits the lower jaw to rotate in a counterclockwise direction, resulting in a smaller lower anterior face height.

It has also been suggested that the divergent facial types are a result of excessive or diminished alveolar growth and eruption of the posterior teeth to compensate for excessive or deficient growth in the posterior dimensions. Of particular significance for the present discussion is the fact that neither posterior dimension of the face showed differences between the facial types in either sex. It is suggested that the role of posterior facial 
dimensions relative to the anterior dimensions of the face may have been overemphasized.

\section{SUMMARY AND CONCLUSIONS}

The purpose of this study was to examine specific details in the patterns of development in unambiguously selected skeletal open-bite and skeletal deep-bite faces.

Longitudinal data from lateral radiographs of 16 male and sixteen female subjects, covering an age span from 3 through 18 years, were used. These subjects were selected from a total sample of 250 persons on the basis of lower anterior face height taken as a percentage of total face height. Thirty-two subjects qualified for inclusion as representatives of "openbite"/"deep-bite" types (16:16).

1. Open- and deep-bite subjects grow differently. Deep-bite subjects are characterized by increased upper anterior face heights, while increased lower anterior face heights are observed in open-bite persons.

2. Extreme typological differences appear to override the growth characteristics that are usually attributed to sexual dimorphism.

3. Posterior face height and ramal height do not significantly differ between open- and deep-bite subjects.

4. The pattern of development in each facial form is established at a very early age, even before the eruption of the first permanent molars and long before the adolescent growth spurt.

5. A developmental gradient in the timing of the adolescent growth spurt is evident in the five dimensions of the face as follows: female open bite, female deep bite, male open bite, and finally male deep bite.

The findings presented have practical clinical relevance for the timing of orthodontic treatment, the length of the retention period, and the predictability of the occlusal relationship from the mixed dentition to adulthood.

\section{REFERENCES}

1. Sassouni V. The face in five dimensions. 2nd ed. Morgantown, West Virginia: West Virginia University Press, 1962.

2. Schudy FF. Vertical growth versus anteroposterior growth as related to function and treatment. Angle Orthod 1964;34:75-93.

3. Schendel SA, Eisenfeld J, Bell WH, et al. The long face syndrome: vertical maxillary excess. AM J ORTHOD 1977;70:398408 .

4. Wylie WL. The relationship between ramus height, dental/height, and overbite. AM J ORTHOD 1946;32:57-67.

5. Björk $A$. The face in profile: an anthropological $x$-ray investigation on Swedish children and conscripts. Svensk Tandl Tidskr 1947;40(Suppl).

6. Prakash $\mathbf{P}$, Margolis J. Dento-craniofacial relations in varying degrees of overbite. AM J ORTHOD 1952;38:627-73.

7. Sassouni V. Diagnosis and treatment planning via roentgenographic cephalometry. AM J ORTHOD 1958;44:433-63.
8. Muller G. Growth and development of the middle face. J Dent Res 1963;42:385-9.

9. Subtelny JD, Sakuda M. Open bite diagnosis and treatment. AM J ORTHOD 1964;50:337-58.

10. Sassouni V, Nanda S. Analysis of dentofacial vertical proportions. AM J ORTHOD 1964;50:801-23.

11. Hapak FM. Cephalometric appraisal of the open-bite case. Angle Orthod 1964;34:65-72.

12. Atherton JD. The influence of the face height upon the incisor occlusion and lip posture. Dent Pract 1965;15:227-31.

13. Loufty MS. Cephalometric evaluation of deep overbite and anterior open bite in Kuwait school children. Trans Eur Orthod Soc 1973:281-5.

14. Nahoum HI. Anterior open-bite: a cephalometric analysis and suggested treatment procedures. AM J ORTHOD 1975;67: 513-21.

15. Hellman M. Open-bite. INT J Oктнuv 1931;17:421-44.

16. Isaacson JR, Isaacson RJ, Speidel JH, Waring RW. Extreme variation in vertical facial growth and associated variation in skeletal and dental relation. Angle Orthod 1971;41:219-29.

17. Johnson $E$. The Frankfort-mandibular plane angle and the facial pattern. AM J ORTHOD 1950;36:516-33.

18. White E Jr. Skeletal disharmonies associated with anterior open bites. In: Brodie A. Research in the Department of Orthodontics, Graduate College, University of Illinois, from 1951 to 1956. Angle Orthod 1957;27:212-5.

19. Smeets HJL. A roentgenocephalometric study of the skeletal morphology of Class II Division 2 malocclusion in adult cases. Eur Orthod Soc Trans 1962:247-59.

20. Richardson A. A cephalometric investigation of skeletal factors in anterior open bite and deep overbite. Trans Eur Orthod Soc 1967;43:159-71.

21. Fields HW, Proffit HW, Nixon WL, Phillips E, Stanek E. Facial pattern differences in long-faced children and adults. AM J ORTHOD 1984;85:217-23.

22. Nahoum HI. Vertical proportions and the palatal plane in anterior open-bite. AM J ORTHOD 1971;59:273-82.

23. Siriwat PP, Jarabak JR. Malocclusion and facial morphology: is there a relationship? Angle Orthod 1985;55:127-38.

24. Swinehart EW. A clinical study of open-bite. AM I ORTHOD 1942;28:18-34

25. Nanda SK. The developmental basis of occlusion and malocclusion. Chicago: Quintessence Publishing Company, 1983.

26. Trouten JC, Enlow DH, Rakine M, Phelps AE, Swedlow D. Morphologic factors in open bite and deep bite. Angle Orthod 1983;53:192-211.

27. Bishara SE, Jakobsen JR. Longitudinal changes in three normal facial types. AM J ORTIIOD 1985;88:466-502.

28. Bishara SE, Peterson LC, Bishara EC. Changes in facial dimensions and relationships between the ages of 5 and 25 years. AM J ORTHOD 1984;85:238-52.

29. Shuttleworth FK. The physical and mental growth of girls and boys age six to nineteen in relation to age of maximum growth. Mono Soc Rec Child Dev 1939;4(no. 3).

30. Tanner JM. Growth at adolescence. Oxford: Blackwell Scientific Publications Lid, 1962.

31. Hägg U, Taranger J. Maturational indicators and the pubertal growth spurt. AM J ORTHOD 1982;82:299-309.

Reprint requests to:

Dr. Surender K. Nanda

Department of Orthodontics

School of Dentistry

The University of Michigan

Ann Arbor, MI 48109-1078 